\title{
First Postgraduate Forum on Health Sciences of the West Central Region of Brazil and First Forum on Experimental Surgery of the State of Mato Grosso do Sul, Brazil
}

\author{
I Forum de Pós-Graduação em Ciências da Saúde da Região Centro Oeste e I Forum \\ de Cirurgia Experimental do Estado de Mato Grosso do Sul, Brasil
}

\author{
Ricardo Dutra Aydos ${ }^{1}$ \\ 1. Coordinator Postgraduate Program on Health and Development in West Central Region, Federal University of Mato Grosso do Sul, \\ Campo Grande, Brazil.
}

A postgraduate program comprising Master's and Doctor's degrees, recognized by the Ministry of Education (MEC) Commission on Improvement of Higher Education Professional (Coordenação de Aperfeiçoamento de Pessoal de Nível Superior-CAPES/MEC), and within conditions of maintaining itself throughout time. This is a dream that most of High Studies Institutions located in the less developed regions of Brazil have. That is the case of the Federal University of Mato Grosso do Sul (UFMS).

In 1994, there were only two professionals with $\mathrm{PhD}$ at the department of Clinical Surgery of UFMS. So, the question that remained was: how could we have a postgraduate program? We had a long way ahead that began with stimulating our staff on obtaining their Master and PhD degrees. This was not an easy task, since those physicians usually work as Liberal Professionals, with an essential and unique role in their community.

Professor Saul Goldenberg had the boldness of opening the doors of the Medicine School of the Federal University of São Paulo (UNIFESP). With great disposal he welcomed our physicians to the Postgraduate Program of that University. Over twelve years have passed since then, and more than ten physicians from our department have taken their PhD on Surgical Technique and Experimental Surgery at UNIFESP.

However, increasing the number of $\mathrm{PhD}$ professionals was just the beginning. In order to organize a Postgraduate Program, the Professors had to consolidate their researches and develop the task of being advisors. Therefore, we could not have found a better solution than the proposition of a Multi-Institutional Program of Post Graduation on Health Science - West-Central Network. This program was strongly held by its coordinator, Professor Carlos Alberto Bezerra Tomáz, from the University of Brasilia.

The researches and orientation from the advisors of this Network produced the knowledge and the experience necessary to the professionals of UFMS, who are now part of the team of Research Professors from the first Postgraduate Program of UFMS to comprise Doctor's degrees.

The First Postgraduate Forum on Health Sciences of the West-Central Region of Brazil, and First SOBRADPEC [Brazilian Society for Development of Research in Surgery] Forum on Experimental Surgery in the state of Mato Grosso do Sul, Brazil, present part of the work we have developed. The publication of this works in international standards is one of the higher objectives of the research.

The necessity of spreading the knowledge generated at Postgraduate Programs was early perceived by Professor Saul Goldenberg, who founded the journal Acta Cirúrgica Brasileira, official journal of SOBRADPEC, with great vision and perseverance, and turning it to become an international publication, which strongly supports experimental researches. It is indexed in MEDLINE, EMBASE, SciELO.

The Postgraduate Program on Health Sciences of the West Central Region of Brazil, comprising Master's and Doctor's degrees, is in debt with the great persons who supported it all the way, as Professor Goldenberg and Professor Tomáz. Instead of staying at their Universities with all its excellencies, they preferred to invest in supporting smaller Institutions, like UFMS.

This Forum comes to consolidate the long way taken by UFMS, a dream that is now becoming a reality. 